\title{
Sea Turtles in Vietnam: On the Edge of Extinction
}

\author{
Cuong The $\mathrm{Chu}^{1,2}$ and The Duc Nguyen ${ }^{1}$ \\ 1. Institute of Marine Environment and Resources, Vietnam Academy of Science and Technology, 246-Danang, Haiphong, Vietnam \\ 2. Department of Ecology, Environment and Plant Sciences, Stockholm University, SE-106 91 Stockholm, Sweden
}

\begin{abstract}
Five species of foraging and breeding sea turtles have been identified in Vietnam, they are Green turtle (Chelonia mydas), Loggerhead turtle (Caretta caretta), Olive ridley turtle (Lepidochelys olivacea), Hawksbill turtle (Eretmochelys imbricata) and Leatherback turtle (Dermochelys coriacea). Among them, with the exception of Loggerhead turtle (Caretta caretta), four species have been being lay eggs on the beaches along the country. However, these populations have been strongly suffered by human activities for decades. The number of foraging and breeding Hawksbill and Leatherback sea turtles has dramatically decreased, and Olive Ridley turtle has almost disappeared on their traditional nesting beaches. Beside the reason of harvesting eggs and nesting turtles by catch or by purpose, the developments in coastal areas where sea turtles laying eggs such as in shrimp aquaculture, tourist resort and residential area developments etc., also contributed to this decline of sea turtles. Despite the fact that the recent raising awareness programs on protection and conservation of the sea turtle were very well done with the participation of many organizations and provinces, this important animals still face the risk of extinction in Vietnam.
\end{abstract}

Key words: Sea turtle; nesting; foraging, threats.

\section{Introduction}

Viet Nam is a marine country with the coast stretching over $3260 \mathrm{~km}$ and a numerous of inshore and offshore islands. In addition, there are ideally habitats for sea turtles such as coral reefs, seagrass beds and sandy beaches located along its coast from North to South. Although records of sea turtles distribution Viet Nam were published very early, the comprehensive study only conducted in 2002 by IUCN Vietnam and some governmental agencies, after Vietnamese government formally ratified the Memorandum of Understanding on the Conservation and Management of Marine Turtles of the Indian Ocean and South-East Asia (MOU IOSEA) [1]. Five among seven species of sea turtle worldwide occur in Vietnamese water (including Loggerhead, Olive ridley, Leatherback, Green and Hawksbill turtles), in almost all provinces from North to South of Vietnam. Four of them used to nest along Vietnamese coast (all except the loggerhead) [2]. In 2004, Vietnam had issued the

Corresponding author: Cuong The Chu, M.Sc., research field: biology and ecology of sea turtles. E-mail: cuongct@imer.ac.vn.
"Marine turtle conservation action plan for Vietnam until 2010", in order to reserve situation and protect the remained marine turtle populations and their habitats in Vietnam. After that, several conservation and management initiatives have been implemented by both the Governmental agencies and the International organisations. The objective of this article is to update the new data of the status and threats to sea turtles in Vietnam.

\section{Materials and Methods}

From 2008 to 2013, we conducted several surveys in the following locations: Quang Ninh province (Bai Tu Long, Co To island), Quang Tri province (Hai An, Trieu Lang, Hai Khe, Trieu Van, Trung Giang, Gio Hai, Vinh Hai), Quang Nam province ( $\mathrm{Cu}$ Lao Cham, Nui Thanh); Quang Ngai province (Hoai Nhon, Phu Cat, Binh Son, Ly Son island); Binh Dinh province (Quy Nhon, Nhon Hoi); Phu Yen province (Song Cau, Tuy An, Dong Hoa); Khanh Hoa province (Cam Lam); Ninh Thuan province (Nui Chua, Ninh Hai); Binh Thuan (Hon Cau island); Ba Ria-Vung Tau province (Con Dao island); Kien Giang province (Phu Quoc island and Tho Chu island) (Fig. 1). 


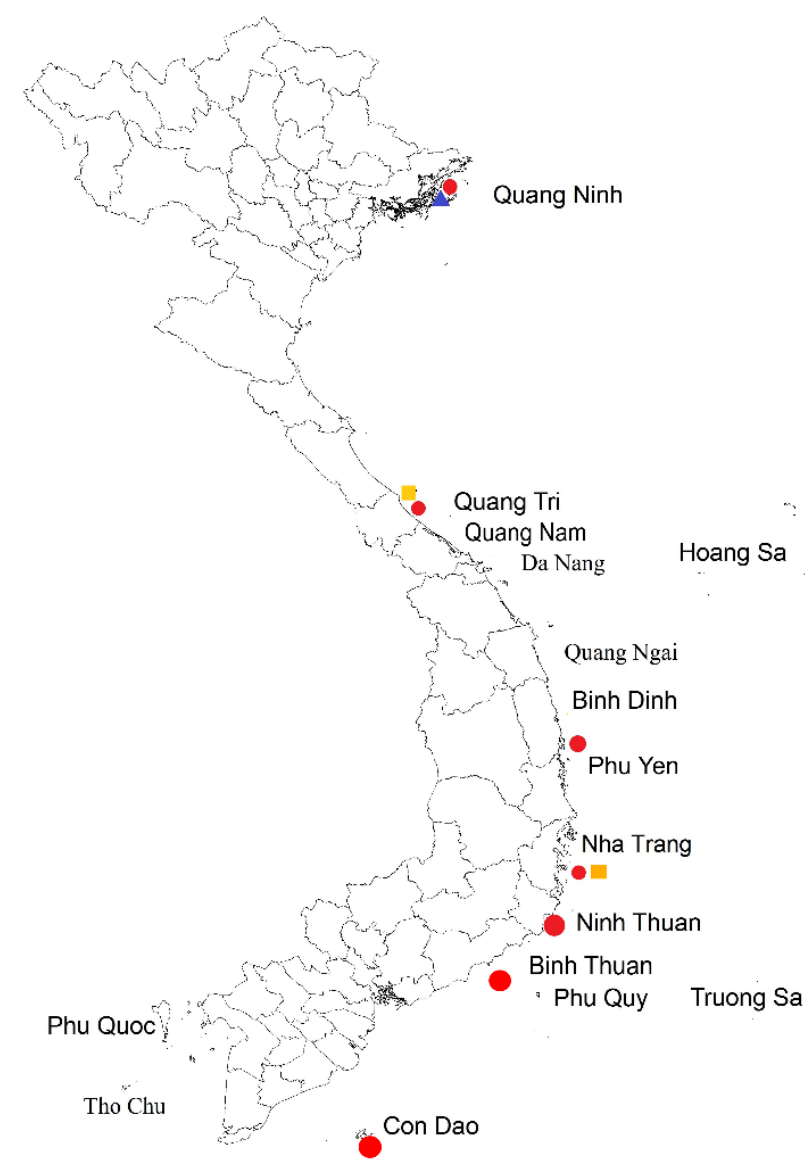

Fig. 1 Distribution of sea turtle breeding populations in Vietnam.

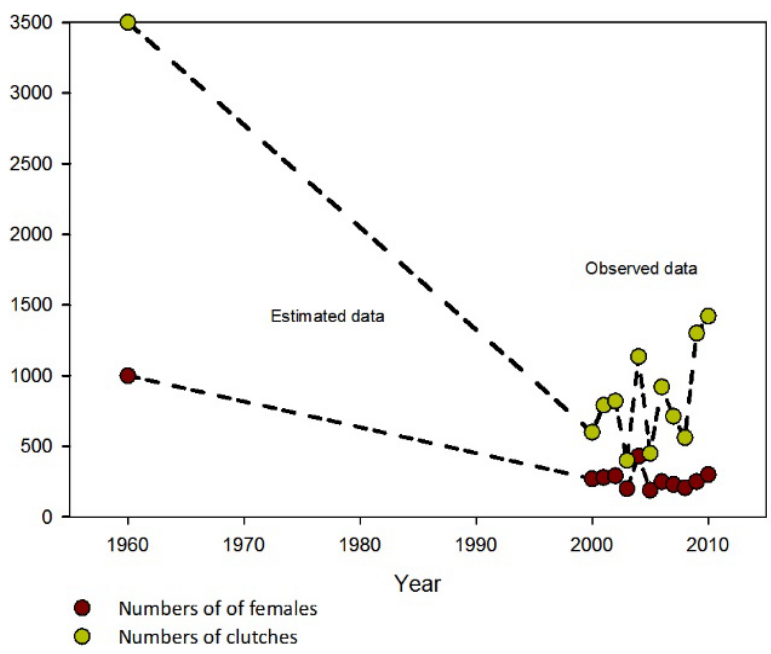

Fig. 2 The trend of Green turtle nesting in Vietnam [2, 4].

In order to obtain initiative information of marine turtle populations in study sites, including nesting and foraging locations, species, by-catch frequency, sizes, tags etc, in each study site we implement interview survey by using (1) questionnaires and (2) lead questions techniques [3]. The questionnaires have been sent to fishermen who participated in the raising awareness workshops. The method of using the lead questions have been applied in discussions with the local authorities and experienced people (ex. Fishermen who used to fishing turtles by purpose, fishery traders, inshore and offshore fishing boat capitals etc.) in order to get the in-deep data of marine turtle populations at study sites. In each location we interview at least 20 people by questionnaire and 5 people by lead questions. In total, we interviewed 600 people in 26 coastal districts.

A form of standard questionnaire was developed and used for all interviews, including following main components: Where and when sea turtle nest on the local beaches, what species of turtle nest, or used to nest on these beaches; estimates the size of nesting, is there any directly catch or indirectly catch sea turtles and what species.

\section{Results and discussions}

\subsection{Status of Breeding Populations}

\subsubsection{Green turtle (Chelonia mydas)}

Overall, the numbers of Green turtle females nesting on Vietnamese rookeries is stable at about 300 individuals (147-422 individuals/year) (Fig. 2). However, the numbers of rookeries is reduced rapidly, especially at unprotected areas. Before the years of 70, Green turtle breeding population distributed in almost all of sandy beaches in Vietnamese coast, reduced to 9 areas in 2002 [2]. In 2013, the number of rookeries is only 7 , including 2 recently added rookeries in the center of Viet Nam (Fig. 1).

Among these recently breeding areas, the Con Dao archipelago is the most important site. The annual average number of breeding females here is $237.92 \pm$ 68.42 individuals/year (ranged from 116 to 379 ) on 14 rookeries $(80 \%$ of them concentrated in 5 rookeries named Hon Tai, Bai Duong, Cat Lon, Hon Cau, Hon Tre) [4]. The areas at Nui Chua National Part (Ninh 
Thuan province) is also a noticeable nesting area, average number of females is from 5 to 8 individuals per season at 3 rookeries (Bai Thit, Bai Dai, Bai Mong Tay). In the north, the Green turtle recently only nests within Bai Tu Long National Park (Nut Dat and Quan LAN islands) and Bai Phung Hoang (Co To Island). However, the number of females and clutches is very few (less than 15 individuals). Quang Tri province used to be a big nesting ground for Green turtles in the part, but at the moment, there is only less than 10 individual nesting on more than $70 \mathrm{~km}$ sandy beaches of province each year. Among three recently confirmed nesting areas, the Hai Giang-Hon Kho (Binh Dinh province) is larger nesting ground of Green turtles with about 10 females per year and other place is a small island in Nha Trang Bay with about 2-4 females per year and Hon Cau island (Binh Thuan province).

\subsubsection{Hawksbill Turtle (Eretmochelys Imbricata)}

Hawksbill turtles were relatively common species in Viet Nam in the past, however, due to widespread and large-scale exploitation for commercial trade, the number of breeding and foraging hawksbill turtles have reduces rapidly [3]. Until the year 2003, small number of hawksbill turtles was still nesting at the beaches in Con Dao archipelago (about 10 clutches and 3 females per year at Ong Dung beach) (personal interview local people in Con Dao) and in Bai Tu Long bay (about 4-5 clutches per year). Nevertheless, under the pressure of harvesting both breeding females at nesting sites and forging adults and sub-adults at feeding grounds for commercial purposes, the number of nesting females of hawksbill is very low at the moment. It is estimated that there are only one or two females now are still nesting at offshore and untouched beaches within Bai Tu Long bay, while nesting population in Con Dao is completely depleted.

3.1.3 Leatherback Turtle (Dermochelys Coriacea)

Leatherback sea turtle is one of the rarest turtle species in Vietnam. Despites they had been widely distributed along Vietnamese coast, the number of nesting female have dropped seriously since 1980s. In the years of 1960s, it was estimated that about 500 breeding females of leatherback turtle each year on the beaches of Vietnam (concentrated on central provinces) but there number was limited to only about 10 females per year in 2000s [2]. Recently, only one beach in Trieu Lang commune (Quang Tri province) has the signs of nesting leatherback in 2005 and 2007 but no clutches data were recorded. In June 2013, a leatherback female had laid a clutch at Bai Dai (Cam Lam district, Khanh Hoa province). But unfortunately, none of these eggs successful hatched. After excavating the nest, total number of eggs was 85 , but only $62(73 \%)$ of them had yolks, the rest $(27 \%)$ had small size and no yolks. The eggs then have been opened, all of them were unfertilized.

3.1.4 Olive Ridley Turtle (Lepidochelys Olivacea)

Olive ridley turtle were one of the most common species of marine turtle in Vietnam few decades ago. Nevertheless, after a long period of overexploitation, until 2003 the number of breeding population was fallen to less than 40 individuals per season, breeding sites were limited to Quan Lan island (Bai Tu Long Bay-Quang Ninh province), Son Tra Peninsula (major nesting site in Da Nang City), and some beaches in Quang Binh province [2]. At the moment, none of above sites has nesting females crawled. The main reason for this phenomenon is the development of tourism industry in the coastal areas. For instance, after the road around Son Tra peninsular has been built, and all nesting beaches there was filled with a number of luxury resorts, as a result, marine turtle have no peace and quiet place to lay eggs and they disappeared completely in this area.

\subsection{Status of Foraging Populations}

Vietnam provides extensive foraging habitat for five species of marine turtle, including Green turtle, Hawksbill turtles, Loggerhead turtles, Olive ridley turtle and Leatherback turtle [2]. Even through the 
size of foraging turtle populations in Vietnam is unknown, but based on frequency of seeing or capturing marine turtles in foraging grounds, it could be concluded that green turtle is the biggest population and distribute in almost all coastal provinces of Vietnam, the second is hawksbill turtle and olive ridley turtle, leatherback turtle and loggerhead turtle now are rarely found in the wild. While green turtle is herbivorous species, they are often found on seagrass areas, especially at Phu Quy island (Binh Thuan province), Phu Quoc island (Kien Giang province), Con Dao island (Ba Ria - Vung Tau province), Truong $\mathrm{Sa}$ archipelago (Khanh Hoa province), Hoang Sa (Da Nang) and Bach Long Vy island (Hai Phong province. Other species (except leatherback turtle) are usually distributed in coral reefs or rock reefs areas and fishing grounds such as Bai Tu Long bay (Quang Ninh province), marine area along the coast of the central provinces from Quang Tri to Binh Thuan province, Truong Sa (Khanh Hoa) and Hoang Sa (Da Nang) [5]. However, their numbers have been reduced rapidly recently due to a long period of over-exploitation. Leatherback turtles are even rarer, with very little information of their appearance in Vietnamese water at the moment.

\subsection{Threats to Sea Turtles}

\subsubsection{By-catch Exploitation}

The incidental capture of marine turtles is a large and widespread problem, with a large percentage of these either drowning in fishing gear or being killed for food when caught in nets and brought aboard alive. The rate of by-catch marine turtles by long line fishing vessels operating in around Truong $\mathrm{Sa}$ archipelago and $\mathrm{Tu}$ Chinh fishing ground was 57\% (including 4 Olive ridley turtles, two Hawksbill turtles, one Green turtle and one Leatherback turtle in 14 trip). In 2006, the total number of long-line fishing boats in Vietnam is 1,670 units, concentrated in Da Nang, Quang Nam, Quang Ngai, Binh Dinh, Phu Yen, Khanh Hoa, Ninh Thuan, Ba Ria-Vung Tau, Ho Chi Minh and Kien
Giang [5]. Each season, a long-line vessel usually goes to fishing ground 3 to 4 trips. Therefore, the number of marine turtles which are caught by only long-line fishing method is approximately 3,000 individuals per year. However, this could be overestimated due to limitation of study trip (only 14 trips) and in a short time (one fishing season) and need to have further studies.

\subsubsection{Collecting Eggs and Nesting Females}

At the moment, these harvest activities have reduced rapidly. With the promulgation of Environmental Protection Law (2005), Biodiversity Law (2008) and other related legal legislations, the authorities have had useful tools to deal with violations. Other reasons are the critically reduction of marine turtles appear on the beaches of Vietnam and the effective of several rising awareness programs in conservation and protection marine turtle. However, at almost all of unprotected rookeries (in Quang Tri, Quang Ngai, Binh Dinh, Phu Yen, Truong Sa, Phu Quoc, Tho Chu etc.), eggs and breeding adults have collected illegally and they were consumed locally and rarely sold in the market. Some fishermen from Quang Ngai and Binh Dinh have been sentenced to prison in Philippine and Malaysia because of catching sea turtles. According to their testimonies, most of sea turtles would be sold to buyers from Hainan, China.

\subsubsection{Loss of Nesting and Foraging Habitats}

The beaches on which turtles are still occasionally nesting are mostly undeveloped and/or located on offshore islands, away from tourism. However, many beaches in Vietnam now are earmarked for tourist development. If these beaches are developed, marine turtle nesting rookeries may be threatened by a variety of factors such as beach removal or alteration, physical obstruction to the dunes, lighting, noise, and increased beach use by people. The beaches in $\mathrm{Cu}$ Lao Cham island (Quang Nam), Son Tra peninsula (Da Nang), the favorite nesting sites of Olive Ridley and Green turtles have been completely wiped out, as the consequences of tourist developments in these areas. 
Besides, the increase in number of industrial zones along the coastline (for example in Quang Ngai province) and sand mining (in Quang Tri and Binh Dinh provinces) are also two great threats to sea turtle populations in this areas.

The most important and obvious threat to the nesting habitats of sea turtles in the central provinces is the shrimp farming on beaches. This aquaculture method has been introduced in the central provinces since years of 90s and seemed to be very effective in few first years. As a result, it has been recommended by several governmental authorities and expanded from small and experimental scale to industrial scale. According on our observation, shrimp ponds could be found in almost all beaches, from extensive farming in family scale to well-projected, intensive farming in industrial scale. The most abundance is in Quang Tri, Quang Ngai and Binh Dinh respectively. The impacts of this aquaculture technique to environment and biodiversity have been proved by many researches, such as changing the underground water system (fresh underground water should be taken locally to reduce the salinity of shrimp ponds), waste water (which contains many chemical elements, anti-biotic, organic substances etc.) discharge directly to the sea etc. Besides, these ponds are located on high-tide area, where is also the nesting place of sea turtles. Most of the beaches we visited had extremely high levels of marine debris. Much of this debris was glass, plastics and polystyrenes, and other items associated specifically with fishing such as floats, nets, and light bulbs. This is a problem for sea turtle nesting because it may impede movement and nest digging, lead to injury and infections, and in some cases may cause turtles to be trapped. However, the number of dead or injured individuals along the coast of Vietnam is unknown.

\section{Conclusions}

Even though several activities have been conducted to protect sea turtles in Vietnam, the number of species and rookeries has been decreased in comparison to the previous data from years. At present, only Green turtle is remaining its number, other species such as Hawksbill and Leatherback sea turtles have dramatically decreased, and Olive Ridley turtle has almost disappeared on their traditional nesting beaches. Beside the reason of harvesting eggs and nesting turtles by catch or by purpose, the developments in coastal areas where sea turtles laying eggs such as in shrimp aquaculture, tourist resort and residential area developments etc., also contributed to this decline of sea turtles. Despite the fact that the recent raising awareness, these important animals still face the risk of extinction in Vietnam in the future.

\section{Acknowledgments}

The authors gratefully acknowledge the Vietnam Academy of Science and Technology (Project VAST.DLT.03/12-13), Project KC 09.08/11-15 and Project KC 08.25/11-15 for providing financial support. The authors also thank the staff of the Institute of Marine Environment and Resources, Sub-departments of Capture Fisheries and Resources Protection in Quang Tri, Quang Ngai, Binh Dinh, Phu Yen, Bai Tu Long Nation Park, Con Dao National Park, Nui Chua National Park, Chu Lao Cham MPA, Phu Quoc MPA, Phu Quy MPA, Con Co MPA for their efforts in collecting data.

\section{References}

[1] Hamann, Mark, Hien Bui Thu, Nick Cox, Julie Thompson, Chloe Schaeuble, Cuong Chu The, Khuong Tran Chinh, and Hong Nguyen Duy 2005. "Marine Turtle Conservation in Viet Nam-Towards 2010." Marine Turtle Newsletter 107: 5-6.

[2] Hamann, Mark, Chu Cuong, Nguyen Hong, Pham Thuoc, and Bui Thuhien 2006. "Distribution and Abundance of Marine Turtles in the Socialist Republic of Viet Nam." Biodiversity and Conservation 15 (11): 3703-20.

[3] Eckert, K. L., et al. (eds.) 1999. Research and Management Techniques for the Conservation of Sea Turtles. IUCN/SSC Marine Turtle Specialist Group Publication. Vol. 4, Washington DC.

[4] Giang, Nguyen Truong, 2008. The Final Report-Sea 
Turtle Conservation Project in Con Dao, edited by Con Dao National Park, 38. Baria-Vung Tau: WWFIndochina.

[5] Dung, Phan Hong, Nguyen Thi Dieu Thuy, and Keith Symington, 2007. Preliminary Assessment of Hotspots and Recommended Next Steps for Onboard Fisheries Observer Program. In: Improving the knowledge base and identifying management options for the reduction of sea turtle interactions in Vietnamese fisheries, 40. Ha Noi: WWF. 